\title{
Tamlayanın Sergüzeşti
}

\author{
Yeșim Tütün
}

Karamanoğlu Mehmet Bey Üniversitesi, Sosyal Bilimler Enstitüsü, KARAMAN

\begin{abstract}
Özet
Genetif eki, İsmi genetif haline sokan ektir. Bir isim tabi olduğu başka bir isme genetif halinde bağlanır. Bunun için isim genetif eki almadan eksiz genetif şeklinde bulunur veya genetif eki alarak ekli genetif şekline girer: İ́stanbul (şehri), yemek (odası); taş-1n (üstui), ev-in (yolu), yol-un (iyisi); oda-nın (içi), bebenin (maması), uyku-nun (sonu) misallerinde olduğu gibi.

Göktürk Kitabelerinden günümüze kadar varlığını gördüğümüz tamlayan eki, ekleşme sürecini geçirdikten sonra günümüzdeki halini almıştır."nynk" yani tamlayan eki ekleșme sürecini dört kısımda inceleyeceğiz. "nynk" eki ilk olarak hem ek hem de bağımsız kelime olarak "șey,nesne, mal, eșya" anlamında kullanılmıştır. Ayrıca ek olarak kullanıldı̆̆ı zaman kelimeden ayrı yazılmaktaydı. Zamanla kelime anlamını yitirmeye başlamış ve edat olarak da kullanılmıştır. Ekleşme süreci içerisinde ses değişikliğine uğramış ve kelimeye bitişik halde yazılmaya başlamıştır. "nynk" ekinin ekleşme sürecine dair örnekleri bildirimizin içersinde yer vereceğiz.

Genel olarak bildirimiz de "nynk" tamlama ekinin ekleşme sürecini ele alacağız.

Anahtar Kelimeler: Tamlayan eki, ilgi hal ekleri, ekleşme süreci, gramatikalizasyon.
\end{abstract}

\section{The Change Process Of Genitive Suffix}

\begin{abstract}
The genitival suffix is the suffix which changes the noun into genitive state. A noun is connected to another noun to which it is related in its genitive state. For that the noun stands without getting a genitive adjunctor it turns into genitive state by getting a genitive adjunct: as it happens in theseexamples : İstanbul (şehri), yemek (odası); taş-ın (üstï), ev-in (yolu), yol-un (iyisi); oda-nın (içi),

The genitival adjunct whose existance can be seen from Göktürk epitaph stil now , has got its current state after passing the adjunctification process. We will analyse the genitival adjunction 'nynk' adjunctification in 4 parts.At first, the adjunction 'nynk' had been used as both adjunction and indepentdent word 'thing, object, good, material'.Furthermore it was written seperate from the word when it was used as adjunction. By and by the word began lose its meaning and used as preposition. During the adjunctification process it had been sustained to sound change and it began to be written close to the word. We will give the examples about adjunctification process in our report.

In general we will handle the genitival adjunctification process of the genitival suffix in our report.
\end{abstract}

Keywords: Genitival suffix, state suffixes, adjunctification, gramaticalisation.

\section{Giriş}

Eklerin büyük bir çoğunluğunun tam olarak nasıl ve ne şekilde ortaya çıktığını belirlememiz mümkün değildir.En eski kaynaklardan itibaren yola çıkarak nasıl bir süreç geçirdiklerini belirleyebiliriz. Kökeni çok eskilere dayanan Türkçede eklerin nasıl ortaya çıktığını belirlememiz mümkün olamamakla birlikte eklerin geçtiği aşamaları belirlememiz mümkündür. Bunun içinse Türkçeye ait ilk yazılı metin Göktürk Abidelerinden başlayarak günümüz Türkçesi eserlerini incelediğimizde eklerin ses bilgisi ve anlam bilgisi bakımından çeşitli basamaklardan geçerek ek haline geçtiğini görmekteyiz.

Bağımsız sözcüklerin bir takım aşamalardan (bağımsız,edat, ek) geçerek ek haline gelme sürecine ekleşme " Gramatikleşme" denir. Bir sözcüğün ekleşme süreci ise oldukça uzundur. Türkçenin eklerinin bir kısmı, başlangıçta bağımsız bir kelime iken daha sonra ekleşerek günümüzdeki kullanım şekillerine dönmüştür.

$\mathrm{Bu}$ süreci yaşayan eklerden biri de "nynk" tamlayan ekinin olduğunu görüyoruz. Göktürk Abidelerinden itibaren varlığını gördüğümüz "nynk" eki anlam ve ses bilgisi bakımından çeşitli aşamalardan geçmiştir. Başta kelimeden bağımsız olarak kullanılan bu ek zamanla ekleşme sürecine girmiş ve kelimeye bitişik halde yazılmaya başlamıştır. "nynk" gramatikleşme çerçevesinde ele alacağız.

\section{2. İlgi Hal Eki}

Zeynep Korkmaz, ilgi hal ekini tamlamalarda bir ismin başka bir isimle ilgili olma hâli. Bu hâl +In /+nIn +Un/+nUn ekleriyle karşılandığını belirterek şu örnekleri vermektedir: ağaç+ın yaprağı, kitab+ın kapağı, okul+un bahçesi vb. Tamlamalarda tamlayan görevindeki isim ilgi ilişkisini ilgi hal eki almadan da kurulabiliceğini söyler. ağaç kabuğu, yağmur havası, toprak kokusu vb. örneklerinde olduğu gibi.

Ancak adı geçen tamlamalarda, tamlanan isim belirsiz bir isim durumundadır. Ev+in kapısı belirli bir evin kapısı olduğu halde, ev kapısı herhangi bir evin kapsıdır. (Korkmaz 1992: 87)

Ahmet Topaloğlu ise Türkçe bağlamlık, genetif (hali) -in hali, türlük düşüm,ilgi hali, tamlayan durumu, katılma hali, kimin hali isimlerini veriyor.

Ve ilgi hal ekini şu şekilde tanımlıyor: İsim tamlamalarında bir kavramın başka bir kavrama bağlandığını, onunla tamamlandığını gösteren hal. Bugünkü Türkçede ilgi halinin -In ve _nIn ekleriyle yapıldığını belirtiyor. at+ın ayağı, ev+in odası, okul+un bahçesi, göz+ü rengi vs. 
örneklerini veriyor. Bu hal eksiz olarak da oluşturulabildiğini saray odası, göz bebeği, komşu çocuğu vs. örnekleriyle aç1klıyor. (Topaloğlu 1989: 89)

Vecihe Hatipoğlu, ilgi haline "Tamlayan durumu" adını veriyor. Ad görevindeki sözcüğün taşıdığı kavramın başka bir kavrama bağlanması durumu olduğunu Türkçede bu durum ın(-in,-ün,-un;-nın,-nin,-nun,-nün) ekleriyle kurulduğunu belirterek şu örnekleri veriyor: Evin (ev-in), taşın(taş1n), çocuğun( çocuğ-un). (Hatipoğlu 1981: 116)

Tahsin Banguoğlu, ilgi haline Kimin hali adın katılma halidir(genetif) diyor. Bu haldeki adların sahip olanı, tabi olunanı, kapsayanı gösterdiklerini ve bir sahip olunanı, tabi olanı kapsananı gerektirdiklerini belirtiyor. Bunun sonucunda da iki türlü soru açtıklarını aşağıdaki şekilde açıklamamaktadır.

\section{Ne Durmuş-un-dur?}

Durmuş-un ne-si?

Kimin halinde adlar birinci soruyu yüklem ismi olarak karşılamaya yararlar;

Güvercinler Durmuş-un-dur. sütçününmüş.

$\mathrm{Bu}$ bahçe

Kimin halinde adlar ikinci soruya bir belirli ad takımı ile cevap verirler:

bahçe_si

Durmuş-un oda-sı Sütçü-nün ineğ-i Kardeşimin

Görüldüğü gibi bu ikinci kullanışta sahip olunan, tabi olan sonra gelir ve bir iyelik eki aldığını belirtiyor.(Banguoğlu 2011: 328)

Muharrem Ergin ise ilgi halini şu şekilde tanımlamaktadır: İsmi genetif haline sokan ektir. Bir isim tabi olduğu başka bir isme genetif halinde bağlanır. Bunun için isim genetif eki almadan eksiz genetif şeklinde bulunur veya genetif eki alarak ekli genetif şekline girer: İstanbul (şehri), yemek (odası); taş-ın (üstui), ev-in (yolu), yol-un (iyisi); oda-nın (içi), bebe-nin (maması), uyku-nun (sonu) misallerinde olduğu gibi.

Ergin, ilgi hali ekinin eski devrelerde ve bugün ağızlarda bu ekin farklı şekilde kullanıldığını vurgular. Ekin sonundaki

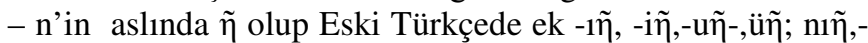

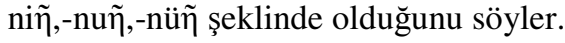

Ayrıca Ergin, ilgi hal ekinin Eski Anadolu Türkçesi'nde ise ekin yalnız yuvarlak vokalleri şeklinde olduğunu "Taş-uñ, ev-üñ, ata-nū̃, dere-nüñ "örnekleriyle açıklar. Ekin vokalinin ancak Osmanlıca içinde uyuma bağlanmış, öte yandan İstanbul Türkçesi sağır kefleri attığı için son zamanlarda yazı dilinde ek n'leşmiş ve böylece bugünkü halini aldığını da söyler.

Genetif ekinin üç yerde kullanım fonksiyonunun olduğunu şu şekilde açıklar:

-İsmi isme bağlar. Ekin asıl fonksiyonu vardır. Orhanındır,senin olsun..

-İsmi fiile bağlar. Tam bir hal eki durumunda gözükmekte ve bulunduğu isim fiilin zarfı olmaktadır.

-Genetif eki zamirleri bazı edatlara bağlamakta kullanılır: senin için, onun için.gibi bu durumda genetif eki mana bakımından değil, sadece şekil bakımından görevi vardır.
Yani ismi edatların aslı olan başka bir isme bağlanmaktadır. ( Ergin 2012: 328-329)

Göktürkçede ise kelimelerden sonra $+\mathrm{I} \tilde{\eta}$

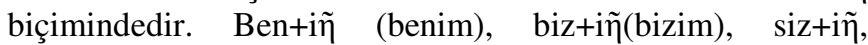

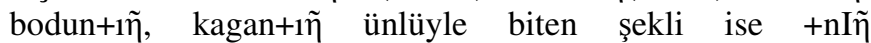
biçimindedir. Bayırku+nı̃̃. (Ercilasun 2004: 185)

Uygurcada ise y Ağzında ilgi hal eki ünsüzlerden sonra + nI $\tilde{~}$ olmuştur. $\mathrm{n}$ Ağzında ise ilgi hal ekinin ünsüzlerden sonra bazen $+\mathrm{X} \tilde{\eta}$ olmuştur. (Ercilasun 2004: 280)

Göktürkçe'de ilgi hali eki ünlülerden sonra + Iñ , ünsüzlerden sonra + nI $\tilde{\eta}$ biçiminde iken Uygurcada hem ünlülerden hem de ünsüzlerden sonra + nI $\tilde{\eta}$ biçimindedir. tengrilerniñ, adınlarnı̃̃. ( Ercilasun 2004: 282)

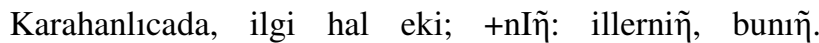
(Ercilasun 2004: 352)

Çağatay Türkçesi'nde de aynı şekilde +nIñ yanında $+n I$ ilgi hal ekinin olduğunu da görmekteyiz; Afrasiyabın oglı. İlgi hal ekinin Çağatay Türkçesi'nde yalnız düz biçimleri vardır; yolnı̃̄, kȫ̃lümniñ.(Ercilasun 2004: 431)

Eski Oğuz Türkçesi’nde ise ilgi hal eki ünsüzlerden sonra $+U \tilde{\eta}$, ünlülerden sonra $+n U \tilde{\eta}$ biçimindedir: vücuduñ, evǖ̃ , ananũ̃. (Ercilasun 2004: 459)

İdil Bulgarcası'nda ilgi hal eki $+n+1 n$ : Ya'kut+1n belüwi (Yakutun mezar taşı), Ahmad Aga+n 1lgıçisi (Ahmet Ağa'nın y1lk1c1s1). (Ercilasun 2004: 214)

Azerbaycan Türkçesi'nde; ilgi hal eki, ünsüzle biten isim kök ve gövdelerinden sonra $+\mathrm{In} /+\mathrm{Un}$; ünlü ile biten isimlerden sonra ise $+n I n /+n U n$ biçimindedir. Nizaminın ơsoürları, gül+ün rỡngi, gala+nın alınması. .(Ercilasun 2007: 194)

Türkmen Türkçesi’nde ; ilgi hal eki, ünlüyle biten

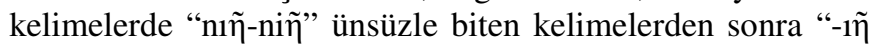

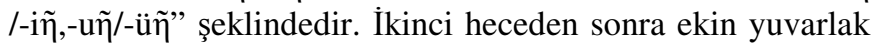
şekli kullanılmaz: daaşı̃̃ "taşın”, depợợnin "tepenin”, üzümiñ “üzümün”.(Ercilasun 2007:256)

Özbek Türkçesi'ine ise ilgi hal eki hep +ning şeklinedir: bợş-ning, bợloọ-ning,qol-ning. Sadece teklik birinci ve ikinci şahıs zamirlerinde +ing biçimindedir: mening "benim", sening "senin". Ekin aitlik eki ile birlikte kullanıldığı kalıplaşmış +niki şekli de vardır. Biz-niki "bizimki”, siz-niki “sizinki”, bộloộ-niki “çocugunki”.(Ercilasun 2007:311)

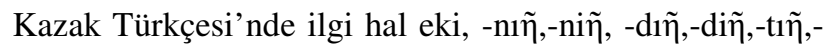
tiñ şeklindedir. Bala-nı̃̃ kiyimderi "çocuğun elbiseleri", üyler-dĩ̃ aldı "evlerin önü”, ağaş-tın köleñkesi "ağacın gölgesi”.(Ercilasun 2007: 451)

Tatar Türkçesi'nde ise ilgi hal eki, -nı̃̃/-něñ şeklindedir. kayınnı̃̃ "kavağın", imenněñ "meşenin", tavlarnı̃̃ "dağların”, yözěgemněñ "yüzüğümün”. (Ercilasun 2007: 709)

Başkurt Türkçesi'nde ilgi hali eki, kalınlık, incelik, yuvarlaklık, düzlük, tonlu tonsuz uyumlarına uyar. Buna bağlı olarak ünlüyle biten isimlerden sonra +

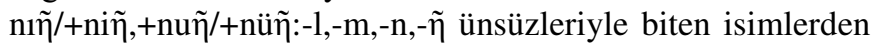
sonra ise $+\mathrm{d} 1 \tilde{\eta} /+\mathrm{di} \tilde{\eta},+\mathrm{du} \tilde{\eta} /+\mathrm{dü} \tilde{\eta} ;$ tonsuz ünsüzle biten

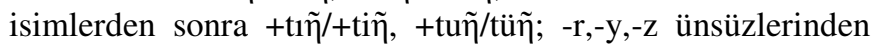

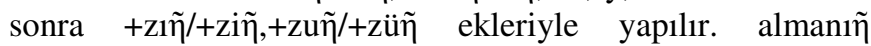
“elmanın”, ikmọkktiñ “ekmeğin”,tawzın “dağın”. (Ercilasun 2007: 766) 


\section{3. "nynk" Eki ve "nynk" Ekinin Ekleşme Süreci}

Bazı kelimler zamanla önce edat olup sonrasında ise ekleşmesine gramatikleşme deniliyor. Bu gramatikleşme süreci ise şu şekildedir:

1- Anlam bilimsel zayıflama

2- Söz dizimsel zayıflama

3- Ses bilimsel zayıflama

Bu süreçte ise geçirilen aşamalar şu şekildedir:

1

\section{Söz Dizimselleșme}

3

\section{Ses Bilimselleşme}

(Lehmann 2002:12)

Nynk tamlayan eki de ekleşme süreci içerisinde anlam ve biçim değişikliğine uğramıştır. $\mathrm{Bu}$ değişikliği gramatıkalizasyon çerçevesinde dört kısımda incelemeye çalışcağız. Nynk eki ilk zamanlarda tamlayan eki olarak ve "şey" anlamında kullanılmıştır. Bunun yanında tamlayan eki olarak da kullanılmıştır. Grönbech Sprachbau'da nynk ekinin şey anlamının yanında başlanğıçta ilgi hal ekinde -niñ olarak telaffuz edildiğini belirtmiştir.(Hamilton 1998: 204)

Göktürkçe de nynk hem tamlayan eki olarak hem de nesne, şey, mal, eşya anlamında kullanıldığını görmekteyiz. $\mathrm{Bu}$ dönem de ağırlık olarak nesne, şey anlamında kullanılmıştır. Ekimiz başta kelimeden bağımsız olarak yazılmaktaydı. Ekleşmeye bağlı olarak zamanla kelime köküne bitişik hale gelmiştir.

Arkış tirkiş 1sar neng bunguğ yok -"kervan, kafile gönderirsen hiçbir sıkıntın yok".

(Ergin 2005:4-5)

Neng neng sabım erser -"her ne sözüm varsa” (Ergin 2005:6-7)

Üçün igidmiş kaġanıngın sabın almatın - “için, beslemiş olan kağanının sözünü almadan".

\section{(Ergin 2005:6-7)}

Olurupan Türk budunung ilin - "oturarak Türk milletinin ilini”" (Ergin 2005:32-33)

Uygur dönemine geldiğimiz zaman ise" nynk" şey anlamının yanında yoğun olarak tamlayan eki olarak kullanıldığını görmekteyiz.

Aysima Mirsultan'nın tez çalışmasında "nynk" ekinin tamlayan eki olarak kullanıldığının bir çok örneğini görebilmekteyiz.

Y1lnı ücünc

v(i)rharnıๆ yüzi

Yyl nynk (Mirsultan $2010: 73-5 / 7)$

vrq'r nynk ywzy (Mirsultan 2010:76-38/16)

Taibazakenı

sökilọ̆rnịka idi

T’yp'ẑ'ky nynk (Mirsultan

$2010: 85-141 / 24)$ swykyl'r nynk (Mirsultan 2010:91-206/20)
Burhanlarnı $\eta$

acariniๆ wendaki

P wra'n l'r nynk'(Mirsultan 2010: 92-220/10)

c'ry nynk (Mirsultan 2010:97-269/11)

Paramitlarnı

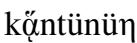

/// myt l'r nynk(Mirsultan 2010:100-298/16) kntw nwnk (Mirsultan 2010: 117-486/18)

Bahsılarnı

nomlarnı

//sỹ l'r nynk (Mirsultan 2010:145-779/11) nwml'r nynk(Mirsultan 2010:172-1066/12)

Şey anlamında kullanıldığı örneklerde bulunmaktadır:

nợๆ adın

nợๆ idi

n'nk 'dyn (Mirsultan 2010:99-288/6)

n'nk 'ydy (Mirsultan 2010:78-64/18)

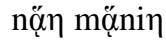

n'nk Om'nynk (Mirsultan 2010: 92-217/7)

Klaus Röhrborn 'un Uygurca metin üzerine yaptığı tez çalışmasında "nynk "ekinin yine hem kelime anlamı olarak hem de tamlayan eki olarak kullanıldığını gösteren bir çok örnek vardır. Bu örneklerden bazıları şunlardır:

Yilnı besic

hanmizniๆ

Yyl nynk(Röhborn 1991:16-10/10)

//nymz nynk(Röhborn 1991:22-88/5)

Yarlignıๆ

tagniๆ kök

Yrlq nynk(Röhborn 1991:24-104/21)

t'q nynk kwyk(Röhborn 1991:24-109/26)

T1ltagnin

yorımaknı

Tylt'q nynk (Röhborn 19191:114-1282/20)

yw ///// //nk(Röhborn 1991:127-1542/20)

Burhanlarn

taplagını

//// l'r nynk(Röhborn 1991:55-507/12)

t'pl'a y nynk (Röhborn 1991:59-568/18)

Larnıๆ süö

larnin

L’r nynk (Röhborn 1991:36-275/27)

/II

/ynk(Röhborn 1991:30-194/1)

örmạgincỡ nọ̆

yapırgaklıgnı

'r ////č n'nk(Röhborn 1991:18-30/2)

y’pyrq'q'’lyq nynk(Röhborn 1991:23-100/27)

Yarlignı

Yrlq nynk( Röhborn 1991:24-104/2)

Nynk “in "şey” anlamında kullanıdığı örnekler ise şunlardır. 
nọ̆

n’nk(Röhborn 1991:18-25/25)

Aysima Mirsultan ve Klaus Röhborn'un metinleri transiterasyon şekilde olduğu için bu eserleri kullandım.

Karahanlılar dönemine geldiğimiz zaman nynk ekimizin halen iki şekilde kullanıldığını görmekteyiz. Kutadgu Bilig' de nynk hem ek olarak hem de kelime anlamı olarak kullanıldığını gösteren örneklere yer verelim.

Ol ilni bügüsi (Arat 2007:s.6-C5/27)

bu mülkniๆ harabi(Arat 2007:s.7-A6/37)

Munıๆ tertibi (Arat 2007:s.7-A6/39)

İkinçi akılık kerek birse neng

Saranka yumıtmaz kişi algu yang (Arat 2007:s.247A87/2325)

Yagıng sü telim tutsa azrak sening

Tokışka ivinme yarag kör anıng( Arat 2007:s.250 C127/2359)

Küler yüz isig söz üle neng tavar

Boş azad kişiler bu üçke avar (Arat 2007:s.254 B181/2408)

Kamug edgülükke neng ol yolçısı

Kamug ig togaka neng ol emçisi(Arat 2007:s.401 C234/3979)

$\mathrm{Bu}$ beglerke tapmak tilese özüng

Köngül til köni tut küdezgil sözüng (Arat 2007: s.403 C235/4000)

Yanut birdi odgurmış aydı sening

Tileking bu erse tilek yok mening (Arat 2007:s.406 C237/4023)

Günümüzde ise "nynk" yavaş yavaş ekleşme süreçlerinden geçerek bağımsız bir kelime olmaktan ve edat olmaktan çıkmış, kelimeye bitişik halde yazılan bir ek konumuna gelmiştir.

Kaymakam bu tezkerenin arkasına laal mürekkebe batmış bir kamış kalemle yazdığı havalede "Kasabanın ahlakı umumiyesini ifsada meydan verilmemek için..." (Karay 2009:7)

Geniş şosenin ortasının sonunda, çevresi bir buçuk arşın kadar yükseklikte...(Ekrem 1992:13)

Bahçenin dışarısına gelince, oda başka bir alemdi...(Ekrem1992:17)

\section{Sonuç}

İlgi hal eki, tamlayan eki, katılma hali, kimin hali gibi çeşitli isimlerle adlandırılan "nynk" eki, uzun bir zaman içerisinde ekleşme sürecinin aşamalarını yavaş yavaş kat etmiştir.Öncelikle bağımsız kelime olarak kullanılmış sonrasında edatlaşmış ve daha sonrasında ise kelimeye bitişik halde yazılan ek halini almıştır. Günümüzde kelime kullanımı kaybolmuş sadece ek halinde kullanılmaktadır. "nynk" eki gibi bir çok ek bu süreçlerden geçerek bugünkü ek halinde ki kullanım şeklini almıştır.

\section{Kaynakça}

Arat, Reşid Rahmeti(2007),Kutadgu Bilig, C.1, Ankara: Türk Dil Kurumu Yayınları.

Banguoğlu, Tahsin(2011), Türkçenin Grameri, Ankara: Türk Dil Kurumu Yayınları.

Ekrem, Recaizade Mahmut(1992), Araba Sevdas1, İstanbul: Morpa Kültür Yayınlar1.

Ercilasun, Ahmet Bican(2004) ,Türk Dili Tarihi,Ankara: Akçă̆ Yayınları.

Ercilasun, Ahmet Bican(2007), Türk Lehçeleri Grameri, Ankara: Akçă̆ Yayınları.

Ergin, Muharrem(2012), Türk Dil Bilgisi, İstanbul: Bayrak Yayınları.

Ergin, Muharrem(2005), Orhun Abideleri, İstanbul: Boğaziçi Yayınları.

Hamilton, James Russel(1998), İyi Ve Kötü Prens Öyküsü, Ankara:Türk Dil Kurumu Yayınları.

Hatipoğlu, Vecihe(1981), Türkçenin Ekleri, Ankara: Türk Dil Kurumu Yayınları.

Karay, Refik Halid(2009), Memleket Hikayeleri 1, İstanbul: İnkılap Kitapevi .

Korkmaz, Zeynep(1992), Gramer Terimleri Sözlüğü, Ankara:Türk Dil Kurumu Yayınları.

Lehmann,Christian(2002),

Thoughts on Grammaticalization Vol. 2, Erfurt: Arbeitspapiere des Seminars für Sprachwissenschaft der Universität Erfurt, No. 9.

Mirsultan, Aysima(2010), Die alttürkische XuanzangBiographie X, Wies Baden: Harrassiwitz Verlag.

Röhborn, Klaus(1991), Die alttürkishche XuanzangBiographie VII, Wies Baden: Otto Harrasowitz.

Topaloğlu, Ahmet(1989), Dilbilgisi Terimleri Sözlüğü,İstanbul: Ötüken Yayınları. 